\title{
Two Different Approaches in Obtaining Head Computerized Tomography Scan in Minor Head Injuries
}

\author{
Nyoman Golden ${ }^{\mathrm{a}, \mathrm{c}}$, Wayan Niryana ${ }^{\mathrm{a}}$, Tjokorda Gde Bagus Mahadewa ${ }^{\mathrm{a}}$, \\ Sri Maliawan ${ }^{\mathrm{a}}$, Ade Chandra ${ }^{\mathrm{b}}$
}

\begin{abstract}
Background: The management of minor head injury (GCS score of 15) especially in the use of computed tomography (CT) scan is still controversial. As a big and developing country, Indonesia faced some problems in the management of minor head injuries. Those problems were limited number of CT scan, big number of minor head injured patients assessed in emergency unit and far distance between small cities and referral centers. This study was aimed to provide different approaches in obtaining CT scan in this group of patients.
\end{abstract}

Methods: This was a cohort prospective study involving 364 head injured patients with a GCS score of 15 , aged over six years. All studied clinical data were recorded and CT scan was obtained. The relationship between the clinical risk factors and the presence of abnormal CT scan (the first end point of this study) and the need for surgery (the second end point) were tested by univariate analysis $\left(\left(\mathrm{X}^{2}\right.\right.$-test). Logistic regression analysis was then used to find the best combination of these clinical factors that were highly sensitive to detect abnormal CT scan and the need for surgery.

Results: The incidence of abnormal CT scan and the need for surgery were $13.2 \%$ and $3.7 \%$ respectively. Loss of consciousness (LOC) (RR 4.84, $95 \%$ CI 1.29 - 18.13), amnesia (RR 4.45, 95\% CI 1.86 - 10.68), cranial soft tissue injury (RR 8.56, 95\% CI 3.43 - 21.46), skull fracture (RR 6.81, 95\% CI 2.04 - 22.77), age $>60$ years (RR 5.56, 95\% CI 2.09 - 14.77) were significant clinical factors of abnormal CT scan. While amnesia (RR 0.068, 95\% CI 0.007 - 0.626), cranial soft tissue injury (RR $0.076,95 \%$ CI 0.009 - 0.647) and skull fracture (RR $0.145,95 \%$ CI 0.035 - 0.607) were significant clinical factors of the need for surgery.

Manuscript accepted for publication July 24, 2013

${ }^{a}$ Department of Neurosurgery, Sanglah General Hospital, School of Medicine, Udayana University, Bali, Indonesia

${ }^{b}$ Departement of Surgery, Sanglah General Hospital, School of Medicine,

Udayana University, Bali, Indonesia

${ }^{\mathrm{c} C o r r e s p o n d i n g ~ a u t h o r: ~ N y o m a n ~ G o l d e n, ~ K e s e h a t a n ~ S t r e e t ~ N o . ~ 1, ~}$

Denpasar, Bali 80114, Indonesia. Email: nyoman_golden@yahoo.co.id

doi: http://dx.doi.org/10.4021/jnr225w
Conclusion: Our recent study provided two different approaches in obtaining head CT scan in minor head injuries, which were dependent on the availability of CT scan and the aim of taking CT scan.

Keywords: Minor head injury; Risk factors; Abnormal CT scan; The need for surgery

\section{Introduction}

Minor head injury is the most common type of head injury assessed in emergency unit. Different definitions had been proposed for mild and minor head injury. Some authors defined minor head injury as GCS score of 13 to 15 [1-3] and others said that minor head injury included patients with GCS score of $14-15$ [2, 4]. Teasdale firstly classified head injured patients with a GCS score of 15 as minor head injury [5]. Many other authors agree with this classification [6-9]. The separation between minor (GCS score of 15) and mild head injury (GCS score of 13 - 14) is essential because the latter has significantly higher incidence of abnormal CT scan, the need for surgery and clinical deterioration [10-15]. Therefore, the use of initial CT scan in head injury with a GCS score of 13 and 14 is in agreement among investigators $[4,10,11,16,17]$.

There are continued debates about which minor head injured patients may require computed tomography in the emergency unit $[4,12,13,18,19]$. This disagreement is driven by the need to immediately detect all patients with potentially serious injury vs. increasing demand to cut increasing medical expenses $[1,4,13]$.

Although GCS score has been widely used to assess head injuries, some investigators think that this scale is less useful to evaluate acute abnormal lesion especially in milder type of head injury $[4,13]$. A small number of patients with a GCS score of 15 have abnormal CT scan and small percentage of them need surgical intervention $[4,11]$. Thus, there must be some other clinical factors in this group of patients who most likely to have a significant risk of developing acute intracranial lesion. Therefore, the objectives of our re- 
Table 1. Patient's Characteristic

\begin{tabular}{|c|c|}
\hline Characteristic & Number $(\%)$ \\
\hline \multicolumn{2}{|l|}{ Gender } \\
\hline Male & $237(65.1 \%)$ \\
\hline Female & $127(34.9 \%)$ \\
\hline \multicolumn{2}{|l|}{ Age (year) } \\
\hline $6-10$ & $30(8.2 \%)$ \\
\hline $10-20$ & $74(20.3 \%)$ \\
\hline $21-40$ & $161(44.3 \%)$ \\
\hline $41-60$ & $55(15.1 \%)$ \\
\hline$>60$ & $44(12.1 \%)$ \\
\hline \multicolumn{2}{|l|}{ Mechanism of injury } \\
\hline Traffic accident & $292(80.2 \%)$ \\
\hline Fall & $62(17.1 \%)$ \\
\hline Assault & $10(2.7 \%)$ \\
\hline \multicolumn{2}{|l|}{ CT Scan } \\
\hline Normal & $316(86.8 \%)$ \\
\hline Abnormal & $48(13.2 \%)$ \\
\hline \multicolumn{2}{|l|}{ Lesions } \\
\hline $\mathrm{EDH}$ & $15(31.2 \%)$ \\
\hline $\mathrm{SDH}$ & $9(18.8 \%)$ \\
\hline Parenchymal lesion & $11(22.9 \%)$ \\
\hline $\mathrm{IVH}$ & $2(4.1 \%)$ \\
\hline $\mathrm{SAH}$ & $8(16.7 \%)$ \\
\hline $\mathrm{EDH}+\mathrm{SAH}$ & $1(2.1 \%)$ \\
\hline Parenchymal lesion $+\mathrm{SAH}$ & $1(2.1 \%)$ \\
\hline Parenchymal lesion + EDH & $1(2.1 \%)$ \\
\hline Neurosurgical intervention & $14(3.7 \%)$ \\
\hline
\end{tabular}

EDH: epidural hematoma; SDH: subdural hematoma; SAH: subarchnoid hemorrhage; IVH: intraventricular hemorrhage.

cent study were; 1 ), to analyze the significance of some clinical factors in detection of abnormal CT scan in this group of patients; 2), to analyze some clinical factors presenting abnormal CT that needs neurosurgical procedure. These two end points will provide different approaches in the use of CT scan in minor head injury.

\section{Materials and Methods}

A prospective cohort study was conducted on 364 patients aged over 6 years with minor head injury admitted at emergency unit, Sanglah General Hospital between October 2011 and February 2012. In this study, a patient was considered suffering from minor head injury when he or she had a blow to the head presented with a GCS score of 15. All patients who had known medical illnesses, suffered from cerebrovascular diseases or intracranial pathology, who were under the influence of alcohol or drugs, who were on blood thinner treatment, had a previous brain surgery, came to hospital more than 12 hours after trauma, had penetrating head injury, had no clear history of trauma and patients with major trauma to other organs that necessitated specialized care in hospital were excluded.

Since we do not have a uniform protocol for obtaining head CT scan on head injured patients, all these patients were evaluated with head CT scan without any additional cost being charged to patients. All head CT scans were initially read by the on-duty neurosurgeon and subsequently reviewed by radiologist. An abnormal CT scan was defined as an acute 
Table 2. Results of Univariate Analyses Associating Clinical Factors and Abnormal CT Scan

\begin{tabular}{|c|c|c|c|c|c|c|}
\hline Risk factors & $\begin{array}{l}\text { Abnormal } \\
\text { CT Scan } \\
(\mathrm{n}=48)\end{array}$ & $\begin{array}{l}\text { Normal } \\
\text { CT Scan } \\
(n=316)\end{array}$ & No (\%) & P value & $\mathbf{R R}$ & $95 \% \mathrm{Cl}$ \\
\hline \multicolumn{7}{|l|}{ LOC } \\
\hline Yes & 45 & 185 & $230(63.2)$ & $<0.001 *$ & 8.74 & $2.77-27.57$ \\
\hline No & 3 & 131 & $134(36.8)$ & & & \\
\hline \multicolumn{7}{|l|}{ Amnesia } \\
\hline Yes & 35 & 79 & $114(31.3)$ & $<0.001^{*}$ & 5.90 & $3.25-10.72$ \\
\hline No & 13 & 237 & $250(68.7)$ & & & \\
\hline \multicolumn{7}{|l|}{ Seizures } \\
\hline Yes & 2 & 2 & $4(1.0)$ & $0.086^{* *}$ & 3.91 & $1.41-10.81$ \\
\hline No & 46 & 314 & $360(99.0)$ & & & \\
\hline \multicolumn{7}{|c|}{ Cranial soft tissue injury } \\
\hline Yes & 35 & 54 & $89(24.5)$ & $<0.001^{*}$ & 8.32 & $4.61-15.00$ \\
\hline No & 13 & 262 & $275(75.5)$ & & & \\
\hline \multicolumn{7}{|l|}{ Vomiting } \\
\hline Yes & 25 & 124 & 149 (40.9) & $0.092 *$ & 1.57 & $0.92-2.65$ \\
\hline No & 23 & 192 & $215(59.1)$ & & & \\
\hline \multicolumn{7}{|l|}{ Headache } \\
\hline Yes & 47 & 250 & 297 (81.6) & $0.002 *$ & 10.60 & $1.48-75.49$ \\
\hline No & 1 & 66 & 67 (18.4) & & & \\
\hline \multicolumn{7}{|l|}{ Fracture } \\
\hline Yes & 21 & 8 & $29(8.0)$ & $<0.001 * *$ & 8.99 & $5.86-13.75$ \\
\hline No & 27 & 308 & $335(92)$ & & & \\
\hline \multicolumn{7}{|l|}{ Age $>60$} \\
\hline Yes & 15 & 29 & $44(12.1)$ & $<0.001^{*}$ & 3.30 & $2.77-27.57$ \\
\hline No & 34 & 286 & $319(87.6)$ & & & \\
\hline
\end{tabular}

${ }^{*}$ Chi-square, ${ }^{* *}$ Fisher's Exact. Significant at $\mathrm{P}<0.05$.

intracranial lesion therefore excluding isolated skull fracture or chronic subdural effusion [20, 21]. Neurosurgical procedure was defined as craniotomy to repair an acute traumatic injury. Placement of an intracranial pressure (ICP) monitoring device was not included in neurosurgical procedure.

From literature review many important clinical factors were associated with acute intracranial lesion $[4,7,11,13$, 19]. On the basis of our previous observation, in this study eight clinical symptoms and signs were selected as clinical factors to be tested in minor head injury at emergency unit.
These factors were LOC, amnesia, seizures, vomiting, headache, cranial softs tissue injury, skull fracture and age over 60 years. LOC was defined as a witness seeing the patients in a state of unconsciousness and reporting this finding to the senior surgical trainee at emergency unit [13]. Amnesia was defined as a patient being unable to describe or remember the incidence that led to head injury [13]. Cranial soft tissue injury was defined as trauma above the eyebrows including abrasion and laceration [22].

History and physical examination of defined variables 
Table 3. Results of Multivariate Analyses Associating Clinical Factors and Abnormal CT Scan

\begin{tabular}{llll}
\hline Risk factors & P value & RR & $\mathbf{9 5 \% ~ C I ~}$ \\
\hline LOC & $0.019^{*}$ & 4.84 & $1.29-18.13$ \\
Amnesia & $0.001^{*}$ & 4.45 & $1.86-10.68$ \\
Cranial soft tissue injury & $0.001^{*}$ & 8.56 & $3.43-21.46$ \\
Headache & 0.135 & 4.93 & $0.61-40.06$ \\
Skull fracture & $0.002^{*}$ & 6.81 & $2.04-22.77$ \\
Age $>$ 60 years & $0.001 *$ & 5.56 & $2.09-14.77$ \\
\hline
\end{tabular}

Logistic Regression *Significant at $\mathrm{P}<0.05$.

were taken at admission by senior trainees under direct supervision by the on-duty neurosurgeon. Patients with normal CT scan were discharged home after a few hours observation in emergency ward. All these patients were provided information on delayed symptoms of intracranial lesion and were suggested to return if they had one of them. Patients with abnormal CT scan findings were hospitalized and treated (surgical or non surgical treatment).

All variables were recorded in binary notation. We used univariate $\left(\mathrm{X}^{2}\right.$-test $)$ to determine the strength between each factor and intracranial lesions and the need for surgery. Logistic regression analysis was then used to find the best combination of clinical factors that highly sensitive to detect acute intracranial lesion and the need for surgery. Relative risk with $95 \%$ confidence interval (CI) was recorded. The level of significance was set at value of less than 0.05 .

\section{Results}

\section{Patient demography and general data}

Between October 2011 and February 2012, 364 consecutive minor head injury were analyzed at our emergency unit. Gender distribution was 237 (65.1\%) male and 127 (34.9\%) female with a mean age of $32.83 \pm 18.20$ years (ranging $6-87$ years). Forty-four patients (12.1\%) aged over 60 years. Traffic accident was the most common mechanism of injury $(80.2 \%)$ followed by fall (17.1\%) and assault (2.7\%) (Table 1$)$.

The most frequent clinical findings were headache $(81.6 \%)$, followed by loss of consciousness $(63.2 \%)$, vomiting $(40.9 \%)$ and amnesia (31.3\%) (Table 2). The incidence of abnormal CT scan was 48 patients $(13.2 \%)$ and abnormal CT that needed surgery was 14 patients $(3.7 \%)$ (Table 1$)$. The most frequent lesion was epidural hematoma $(\mathrm{EDH})$, followed by intraparenchymal lesion. No patients died in this study.

\section{Analysis of clinical factors}

The first end point of this study was abnormal CT scan findings. In univariate analysis LOC (RR 8.74, 95\% CI 2.77 - 27.57), amnesia (RR 5.90, 95\% CI 3.25 - 10.72), cranial soft tissue injury (RR 8.32, 95\% CI 4.61 - 15.00), headache (RR 10.60, 95\% CI 1.48 - 75.49), skull fracture (RR 8.99, 95\% CI 5.86 - 13.75) and age $>60$ years (RR 3.30, 95\% CI 2.77 - 27.57) were signicant variables (Table 2). In multivariate analysis LOC (RR 4.84, $95 \%$ CI 1.29 - 18.13), amnesia (RR 4.45, 95\% CI 1.86 $10.68)$, cranial soft tissue injury (RR $8.56,95 \%$ CI 3.43 - 21.46), skull fracture (RR 6.81, 95\% CI 2.04 - 22.77), age $>60$ years (RR 5.56, 95\% CI 2.09 - 14.77) remained significant variables (Table 3).

The second end point of this study was the need for surgery. In univariate analysis LOC (RR 7.57, 95\% CI 1.00 - 57.25), amnesia (RR 28.51, 95\% CI 3.77 - 215.30), cranial soft tissue injury (RR 40.17, 95\% CI 5.32 - 307.76), skull fracture (RR $28.88,95 \%$ CI 9.65 - 86.38) were significant factors of the need for surgery (Table 4). However, multivariate analysis showed amnesia (RR 0.068, 95\% CI 0.007 - 0.626), cranial soft tissue injury (RR 0.076, 95\% CI 0.009 - 0.647) and skull fracture (RR $0.145,95 \%$ CI 0.035 - 0.607) remained significant factors (Table 5).

\section{Discussion}

Minor head injury (GCS score of 15) is an extremely common entity seen in emergency unit; however, there are various controversial issues in the management of minor head injury such as the use of head CT scan in evaluating mild head injury $[1,4,7,11,13]$ and the definition of seriousness of abnormal CT scan [9]. Many trauma centers obtained CT scans on all minor head injuries on the basis of various significant risk factors $[1,4,7,21]$. In our institution there is 
Table 4. Results of Univariate Analyses Associating Clinical Factors and the Need for Surgery

\begin{tabular}{|c|c|c|c|c|}
\hline Risk factors & $\begin{array}{l}\text { No. of } \\
\text { patients }\end{array}$ & P value & $\mathbf{R R}$ & $95 \%$ CI \\
\hline \multicolumn{5}{|l|}{ LOC } \\
\hline Yes & 230 & $0.019 *$ & 7.57 & $1.00-57.25$ \\
\hline No & 134 & & & \\
\hline \multicolumn{5}{|l|}{ Amnesia } \\
\hline Yes & 114 & $<0.001 * *$ & 28.51 & $3.77-215.30$ \\
\hline No & 250 & & & \\
\hline \multicolumn{5}{|l|}{ Seizure } \\
\hline Yes & 4 & 0.146 & 6.92 & $1.16-41.02$ \\
\hline No & 360 & & & \\
\hline \multicolumn{5}{|l|}{ Vomiting } \\
\hline Yes & 149 & 0.482 & 1.44 & $0.51-4.02$ \\
\hline No & 215 & & & \\
\hline \multicolumn{5}{|c|}{ Cranial soft tissue injury } \\
\hline Yes & 89 & $<0.001 * *$ & 40.17 & $5.32-307.76$ \\
\hline No & 275 & & & \\
\hline \multicolumn{5}{|l|}{ Headache } \\
\hline Yes & 297 & $0.082 * *$ & 0.95 & $0.92-0.97$ \\
\hline No & 67 & & & \\
\hline \multicolumn{5}{|c|}{ Cranial fracture } \\
\hline Yes & 29 & $<0.001 * *$ & 28.88 & $9.65-86.38$ \\
\hline No & 335 & & & \\
\hline \multicolumn{5}{|c|}{ Age $>60$ years } \\
\hline Yes & 44 & $0.233 * *$ & 1.98 & $0.57-6.83$ \\
\hline No & 319 & & & \\
\hline
\end{tabular}

${ }^{*}$ Chi-square, ${ }^{* *}$ Fisher's Exact. Significant at $\mathrm{P}<0.05$.

no clear protocol in obtaining CT scan of minor head injury and tends to take head CT scan on all head injured patients regardless of the level of consciousness. This approach, of course, is very costly because CT scan is still relatively expensive and the clinical management is almost not changed by the result of CT scan.

GCS has shortcoming in evaluating minor head injury, as it does not distinguish different degrees of brain damage in patients with a GCS score of 15 [10, 23]. Even patients with a GCS score of 15 arriving at emergency unit may eventually present life-threatening lesion that evolve to coma or even death [24]. Therefore, there must be clinical variables that could be used to screen patients for the necessity of taking an emergent CT scan. Literature reviews revealed that many investigators proposed different clinical parameters in obtaining head CT scan in minor head injuries [4, 10, 12, 19, $21,25,26]$.

Definition of the seriousness of acute abnormal CT scan is in another controversial issue in minor head injury [9]. Some clinicians believed that any intracranial hemorrhage in minor head injuries, no matter how small should be considered serious [11, 21]. Therefore, this group of patients was classified as high-risk mild head injury, and they were considered having the same risk as patients with a GCS score of 13 or 14 [11, 21]. However, other investigators said that serious abnormal CT scan was acute lesion that needs for surgery [2, 8, 20, 27]. Thus, not all acute abnormal CT was considered serious and not all abnormal CT scan should 
Table 5. Results of Multivariate Analyses Associating Clinical Factors and the Need for Surgery

\begin{tabular}{llll}
\hline Risk factors & P value & RR & 95\% CI \\
\hline Amnesia & $0.018^{*}$ & 0.068 & $0.007-0.626$ \\
Cranial soft tissue injury & $0.018^{*}$ & 0.076 & $0.009-0.647$ \\
Skull fracture & $<0.001^{*}$ & 0.145 & $0.035-0.607$ \\
\hline
\end{tabular}

Logistic Regression. *Significant at $\mathrm{P}<0.05$

be identified and treated regardless of the need for surgery. Some reasons were proposed: 1), during observation, the non-surgical lesion did not show any change in mental status or require any intervention $[12,13]$; 2), abnormal CT scan was a poor predictor of final neurologic outcome [13]; 3), the outcome of patient with a GCS score of 15 with abnormal CT scan was the same as those without [28].

Besides incomplete agreement in taking CT scan and controversy in defining the seriousness of acute abnormal lesion in minor head injury, the big number of patients with minor head injury assessed in emergency unit in our country, unavailability to CT scan in all hospitals and far distance between small city and referral centers had led us to conduct this study. This study was expected to provide more flexible choice in obtaining CT scan in this group of patients. Therefore, in this study we set two end points. The first end point was abnormal CT scan, which was found in $13.2 \%$ of total patients. Our finding was comparable to the $15 \%$ rate reported by Shackford et al [29], 17\% rate reported by Gomez et al [10] and 18\% rate reported by Hsiang et al [11]. In our study, factors that were identified to significantly increased the incidence of acute abnormal CT scan were LOC, amnesia, cranial soft tissue injury, cranial fracture and age $>$ 60. Our findings were in agreement with other investigators $[10,21,22]$.

LOC is an important factor of acute intracranial lesion in mild head injury $[16,19-21]$. In large series of fully conscious patients, it was estimated that a history of altered consciousness increased the risk of traumatic intracranial lesion by a factor of 5 [5]. LOC is a clinical symptom that is easily taken from patients who are mostly present at emergency unit in alert condition. Amnesia, which includes both retrograde and antegrade memory disturbance, with intensive anamnesis is not difficult to be recorded either [10]. Our recent study showed that amnesia was not the only a clinical factor of abnormal CT scan but also the need for surgery.

Many investigators agreed that age over 60 is significantly associated with acute abnormal CT [4, 8, 10, 21, 22, $26,30,31]$. Thus, it seems that advanced age patients need special attention and longer periods of observation.
We did not test confusion as a risk factor of abnormal CT scan, because it is confused with a GCS score of 14, which has higher chance to develop abnormal CT scan. Many studies also did not include the term "confusion" as independent risk of abnormal CT scan [4, 20, 21]. In this study, we also did not test neurological deficit because there has been a complete agreement that it is an absolute parameter for CT scan in all type of head injury [9, 29, 30].

The second end point of our study was the need for surgery, which was found $3.6 \%$ of total patients. This also was comparable to the $2.2 \%$ rate reported by Hsiang et al [11], $3.2 \%$ rate reported by Shackford et al [29] and 3.9\% rate reported by Mendelow et al [28]. Kisat et al reported 4.2\% rate, which was slightly higher than that of other reports [18]. In our study, the clinical factors of the need for surgery were amnesia, cranial soft tissue injury and skull fracture.

Cranial soft tissue injury represents external evidence of cranial trauma, which is easily recognized by rural doctors [22]. Our finding was in agreement with the findings of other investigators [8, 9, 20, 22, 25]. Skull fracture as a significant variable of abnormal CT and the need for surgery has been in agreement by many authors [10-12, 16, 21, 25, $32,33]$. Hsiang et al found that the presence of skull fracture in mild head injury increased the need for surgical intervention by a factor of 20 [11]. Mendelow et al reported that a patient with skull fracture and impaired consciousness had a $25 \%$ chance of developing intracranial hematoma, whereas a patient without skull fracture or impairment of consciousness, the risk was one in 6000 [28]. Servadei et al observed significantly more intracranial lesions and the need for surgery in minor head injured patients with a skull fracture than those without [32]. Gomez et al found that the presence of skull fracture in mild head injury significantly increased the incidence of abnormal CT findings and the need for surgery [10]. From a neurosurgical perspective it is very clear that the presence of skull fracture in patients with minor head injury increases the risk of intracranial lesion that is both statistically and clinically highly significant [30].

These two different approaches would be expected to accommodate any aim in obtaining CT scan. The first end 
point may be used to those who do not want to miss any abnormal CT scan and considered all traumatic lesions are serious. This needs availability to CT scan and neurosurgical services in hospitals. This approach of course will be costly. The second end point may be the most important for physician especially working in remote area, that their ultimate concern is not to identify those with abnormal CT scan, but rather to detect those patients who need acute surgical intervention $[20,25]$. From a neurosurgical perspective, the goal of any protocol for management of mild head injury is to identify significant surgical traumatic lesions and to evacuate these before clinical deterioration occurs [16, 27, 30]. Thus, surgical lesion is an absolute indicator of seriousness of injury. In the Canadian rule, traumatic lesion that at greatest risk for requiring neurosurgical intervention is classified high-risk lesion category [2].

The second approach would help physicians to selectively refer this group of patients not only for obtaining CT scan but also for further treatment. In our study, clinical factors of the need for surgery were easily recognized by physicians. Applying this approach would reduce the number of patients with a GCS score of 15 to be referred to neurosurgical center. Our hospital is top referral hospital in eastern territory of Indonesia covering approximately four million people living in Bali and another million living beyond Bali Island. This second approach would reduce the number of minor head injured patients to be referred to our hospital, meaning less emergency patients would be cared in aisles waiting for bed.

\section{References}

1. Stiell IG, Wells GA, Vandemheen K, Laupacis A, Brison $\mathrm{R}$, Eisenhauer MA, Greenberg GH, et al. Variation in ED use of computed tomography for patients with minor head injury. Ann Emerg Med. 1997;30(1):14-22.

2. Stiell IG, Wells GA, Vandemheen K, Clement C, Lesiuk H, Laupacis A, McKnight RD, et al. The Canadian CT Head Rule for patients with minor head injury. Lancet. 2001;357(9266):1391-1396.

3. Haydel MJ, Preston CA, Mills TJ, Luber S, Blaudeau E, DeBlieux PM. Indications for computed tomography in patients with minor head injury. $\mathrm{N}$ Engl J Med. 2000;343(2):100-105.

4. Saboori M, Ahmadi J, Farajzadegan Z. Indications for brain CT scan in patients with minor head injury. Clin Neurol Neurosurg. 2007;109(5):399-405.

5. Teasdale GM, Murray G, Anderson E, Mendelow AD, MacMillan R, Jennett B, Brookes M. Risks of acute traumatic intracranial haematoma in children and adults: implications for managing head injuries. BMJ. 1990;300(6721):363-367.

6. Stein SC, Spettell C. The Head Injury Severity Scale (HISS): a practical classification of closed-head injury.
Brain Inj. 1995;9(5):437-444.

7. Duus BR, Boesen T, Kruse KV, Nielsen KB. Prognostic signs in the evaluation of patients with minor head injury. Br J Surg. 1993;80(8):988-991.

8. Saadat S, Ghodsi SM, Naieni KH, Firouznia K, Hosseini M, Kadkhodaie HR, Saidi H. Prediction of intracranial computed tomography findings in patients with minor head injury by using logistic regression. J Neurosurg. 2009;111(4):688-694.

9. Miller EC, Derlet RW, Kinser D. Minor head trauma: Is computed tomography always necessary? Ann Emerg Med. 1996;27(3):290-294.

10. Gomez PA, Lobato RD, Ortega JM, De La Cruz J. Mild head injury: differences in prognosis among patients with a Glasgow Coma Scale score of 13 to 15 and analysis of factors associated with abnormal CT findings. Br J Neurosurg. 1996;10(5):453-460.

11. Hsiang JN, Yeung T, Yu AL, Poon WS. High-risk mild head injury. J Neurosurg. 1997;87(2):234-238.

12. Turedi S, Hasanbasoglu A, Gunduz A, Yandi M. Clinical decision instruments for CT scan in minor head trauma. J Emerg Med. 2008;34(3):253-259.

13. Miller EC, Holmes JF, Derlet RW. Utilizing clinical factors to reduce head CT scan ordering for minor head trauma patients. J Emerg Med. 1997;15(4):453-457.

14. Jacobs B, Beems T, Stulemeijer M, van Vugt AB, van der Vliet TM, Borm GF, Vos PE. Outcome prediction in mild traumatic brain injury: age and clinical variables are stronger predictors than CT abnormalities. J Neurotrauma. 2010;27(4):655-668.

15. af Geijerstam JL, Britton M. Mild head injury: reliability of early computed tomographic findings in triage for admission. Emerg Med J. 2005;22(2):103-107.

16. Chan KH, Mann KS, Yue CP, Fan YW, Cheung M. The significance of skull fracture in acute traumatic intracranial hematomas in adolescents: a prospective study. J Neurosurg. 1990;72(2):189-194.

17. Dacey RG, Jr., Alves WM, Rimel RW, Winn HR, Jane JA. Neurosurgical complications after apparently minor head injury. Assessment of risk in a series of 610 patients. J Neurosurg. 1986;65(2):203-210.

18. Kisat M, Zafar SN, Latif A, Villegas CV, Efron DT, Stevens KA, Haut ER, et al. Predictors of positive head CT scan and neurosurgical procedures after minor head injury. J Surg Research 2011;1:1-7.

19. Sharif-Alhoseini M, Khodadadi H, Chardoli M, RahimiMovaghar V. Indications for brain computed tomography scan after minor head injury. J Emerg Trauma Shock. 2011;4(4):472-476.

20. Ibanez J, Arikan F, Pedraza S, Sanchez E, Poca MA, Rodriguez D, Rubio E. Reliability of clinical guidelines in the detection of patients at risk following mild head injury: results of a prospective study. J Neurosurg. 2004;100(5):825-834. 
21. Lee YB, Kwon SJ. A more detailed classification of mild head injury in adults and treatment guidelines. J Korean Neurosurg Soc. 2009;46(5):451-458.

22. Borczuk P. Predictors of intracranial injury in patients with mild head trauma. Ann Emerg Med. 1995;25(6):731-736.

23. Culotta VP, Sementilli ME, Gerold K, Watts CC. Clinicopathological heterogeneity in the classification of mild head injury. Neurosurgery. 1996;38(2):245-250.

24. Lobato RD, Rivas JJ, Gomez PA, Castaneda M, Canizal JM, Sarabia R, Cabrera A, et al. Head-injured patients who talk and deteriorate into coma. Analysis of 211 cases studied with computerized tomography. J Neurosurg. 1991;75(2):256-261.

25. Abdul Latip LS, Ahmad Alias NA, Ariff AR, Shuaib IL, Abdullah J, Naing NN. CT scan in minor head injury: a guide for rural doctors. J Clin Neurosci. 2004;11(8):835839.

26. Fabbri A, Servadei F, Marchesini G, Dente M, Iervese T, Spada M, Vandelli A. Which type of observation for patients with high-risk mild head injury and negative computed tomography? Eur J Emerg Med. 2004;11(2):65-69.

27. Smits M, Dippel DW, de Haan GG, Dekker HM, Vos PE, Kool DR, Nederkoorn PJ, et al. Minor head injury: guidelines for the use of CT--a multicenter validation study. Radiology. 2007;245(3):831-838

28. Mendelow AD, Teasdale G, Jennett B, Bryden J, Hessett C, Murray G. Risks of intracranial haematoma in head injured adults. Br Med J (Clin Res Ed). 1983;287(6400):1173-1176.

29. Shackford SR, Wald SL, Ross SE, Cogbill TH, Hoyt DB, Morris JA, Mucha PA, et al. The clinical utility of computed tomographic scanning and neurologic examination in the management of patients with minor head injuries. J Trauma. 1992;33(3):385-394.

30. Servadei F, Teasdale G, Merry G. Defining acute mild head injury in adults: a proposal based on prognostic factors, diagnosis, and management. J Neurotrauma. 2001;18(7):657-664.

31. Stuart G, Yelland JD, Balderson G. 3000 head injuries: a prospective study of patients admitted to Brisbane neurosurgical units. J Clin Neurosci. 1998;5(4):402-405.

32. Servadei F, Ciucci G, Pagano F, Rebucci GG, Ariano M, Piazza G, Gaist G. Skull fracture as a risk factor of intracranial complications in minor head injuries: a prospective CT study in a series of 98 adult patients. J Neurol Neurosurg Psychiatry. 1988;51(4):526-528.

33. Valovich McLeod TC. The Prediction of Intracranial Injury After Minor Head Trauma in the Pediatric Population. J Athl Train. 2005;40(2):123-125. 